\title{
A TRIBUTE TO DR. LUCY H. MURRAY
}

\section{by Elizabeth Cruickshank, 2329 Athol Street, Regina}

In Dr. Lucy Murray's passing on uly 21, 1967, the S.N.H.S. lost a easured member.

Days patterned with happy associaons and experiences will flood the emories of those who knew her well. ssociates will remember a radiant, umorous, informed and dedicated orker whose heart was ever responve to the beauties of nature.

A rare or unusual find, she had to hare. A friendly service, she was er ready to render, time or effort t being considered. Freely she gave herself and her possessions. "That's hat friends are for." A mind endowed ith a mystic sense of wonder, the ever eager delight of youth in all living wild things, was hers.

The quest for beauty is essentially a seeking of the spirit. Life, to Lucy Murray, was meant to be a thing of beauty. As a seeker, she was grateful for generous gifts nature had bestowed upon her.

As life's symphony goes on, memories of rich comradeship, her liveliness, energy and courage will remain with those who knew and loved her, her spirit illuminating all.

Heartfelt sympathy goes to Dr. Jean who has been bereft of a devoted sister.

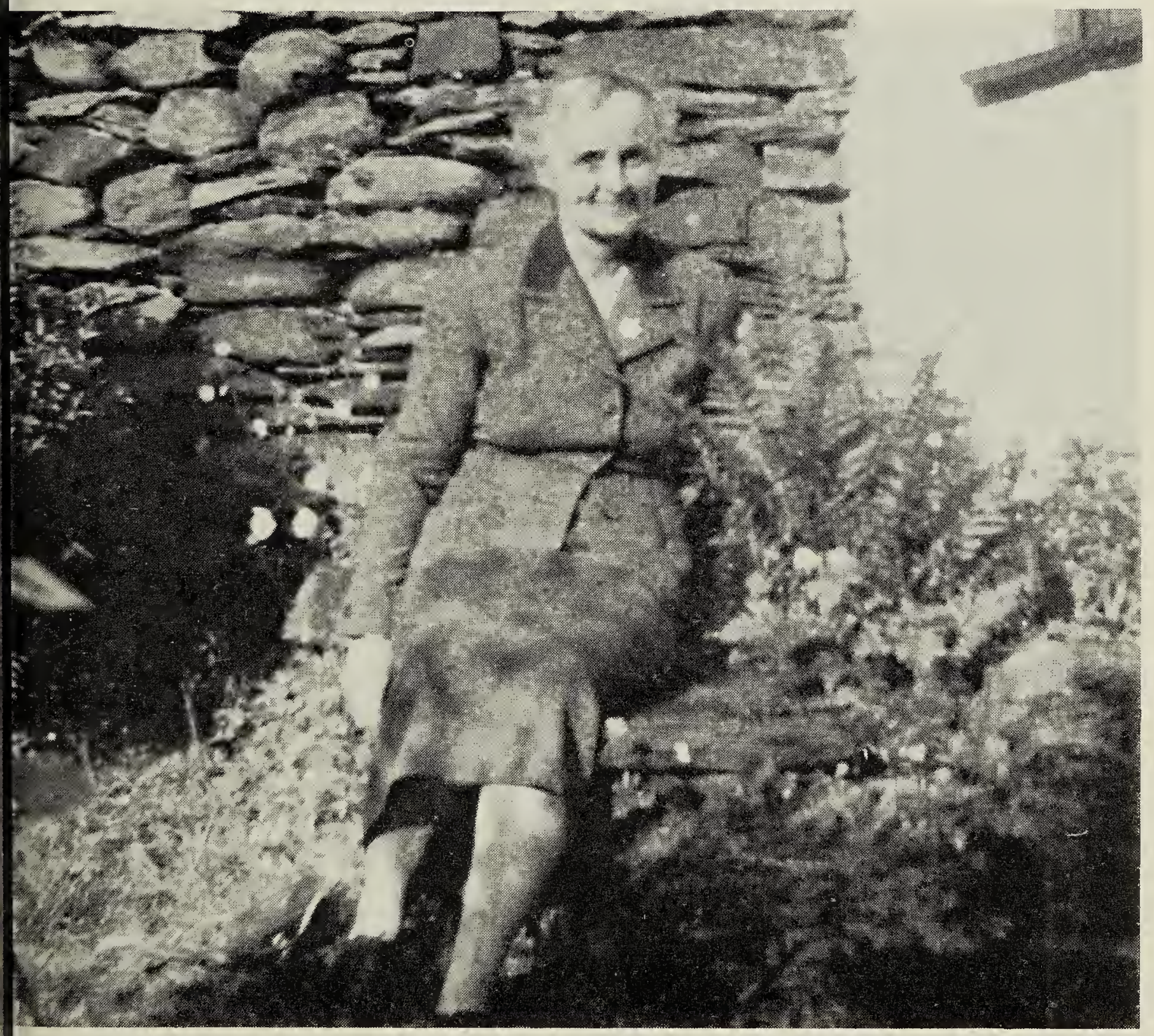

. Lucy Murray at Wordsworth's "Dove Cottage", the Lake District, England, June, 1956. 